\title{
CITATION
}

Bayer, J. B., \& LaRose, R. (20I8). Technology Habits: Progress, Problems, and Prospects. In B. Verplanken (Ed.), The Psychology of Habit: Theory, Mechanisms, Change, and Contexts (pp. III-I30). Cham: Springer.

\section{Technology Habits: Progress, Problems, and Prospects}

\author{
Joseph B. Bayer \\ The Ohio State University
}

\author{
Robert LaRose \\ Michigan State University
}

Technology habits have been objects of research for over Ioo years and provided heuristic cases for the study of habits over the last two decades. This chapter traces the history of research on information and communication technologies in daily life, with an eye toward measurement and conceptualization problems. Similar to the new technologies of earlier eras, the prominence of current habitual manifestations has raised challenging questions for both researchers and societies. These new-er media habits may exaggerate core habitual mechanisms by providing a wide spectrum of potential cues, possible contexts, and complex rewards-resulting in dynamic habits that appear to be "special". We discuss how research on technology habits serves to uncover the assumptions, boundaries, and moderators of habit, while calling for a revised approach to address recurring problems in the literature. Altogether, the chapter clarifies how technology habit research contributes to a broader understanding of habitual behaviour.

Keywords

Internet, Online, Smartphone, Digital, Addiction, Components, Cues, Contexts

At the turn of the twentieth century, an early study on telegraphic habits appeared in Psychological Review (Bryan \& Harter, I899). This long-forgotten article demonstrated how mastery of the telegraph depended on a hierarchal set of habits. And in some ways, not all that much has changed. The habits associated with QWERTY keyboards replaced the core processes found among tele- graphic operators in the twentieth century. Sure, the physical keys and symbols are different, the individual goals and manoeuvres are different, and the surrounding contexts and cultures are different. Yet the habits of grouping automatically selecting keys to represent letters, combining cooccurring letters into words, and words into phrases, endure. 
So, what is the contribution of technology habit research then? This chapter reviews the history of research on technology habits in the fields of communication studies and information systems, while also reflecting on the role of emergent technologies for habit research at large. Along the way, we trace how issues of measurement and conceptualization both challenge and advance the identification of replicable factors that explain technology habit mechanisms, antecedents, and consequences. In doing so, we discuss how technology habits repeatedly appear special, and often addiction-like, by modulating core habitual processes. Responding to the above question, we suggest that studying technology habits helps to elucidate the assumptions, boundaries, and moderators of habitual behaviour more broadly.

\section{What are Tech Habits?}

One of the cyclical challenges in studying technology habits is the question of how to define them, as well as how to describe the set of qualifying behaviours. In the years since the first study of telegraph habits, researchers have directed attention to habits across a range of technological innovations. Do bicycle habits represent a technology habit? Probably not in the contemporary sense, but maybe they should: transportation modes such as stage coaches were synonymous with "communication" before the invention of the telegraph (DeLuca, 20II). Alternatively, bikeshare app usage is likely to be seen as a technology habit today, exhibiting how "technology" focuses not only on the physical object itself but also on the ways in which it is applied. Nonetheless, from a more historical perspective, these innovations are no more technological, or even necessarily social, than old-fashioned bicycles.

Over the last two decades, a myriad of keywords have been applied to organize the everyday habits associated with emergent media, including Internet, electronic, device, gaming, virtual, online, interactive, mobile, digital, network, and information and communication technologies (ICT) habits (LaRose, 20I0a; Limayem \& Hirt, 2003). Increasingly, and owing perhaps to the convergence of traditional mass interpersonal communication systems (Walther \& Valkenburg, 20I7), "technology" is used as a catchall term (e.g. Clements \& Boyle, 20I8; Kuss \& Billieux, 20I7). Of course, if we understand "technology" to be literally "the study of technique", then transportation mode, health, and exercise habits that are said to dominate habit research (Orbell \& Verplanken, 20I5) might also be termed technology habits. In spite of this caveat, we adopt the term "tech habits" here to avoid further fragmentation while reflecting on the state of research progress, with a special emphasis on everyday innovations examined in the fields of communication and information systems.

\section{A Short History: Progress in Tech Habit Research}

Even before the popularization of the Internet and the renaissance of habit research in social psychology in the I990s, habits were a topic of interest in information systems (Limayem \& Hirt, 2003) and communication studies (LaRose, 20IOa, 20I5). Within communication research, for instance, habit research can be traced to a single item in Rubin's (I984) "ritual gratifications" measure ("It's just a habit") that was a predictor of television use. However, the gratifications examined in such work are defined to be actively and consciously processed, so habits cannot be gratifications (LaRose, 20IOa).

As scholarly attention turned from the television to the Internet, habits were found to be significant predictors of diverse patterns of online behaviour, including general Internet use, online shopping, downloading media files, social networking, and online news consumption. Similar to social psych- 
ology research that verified the explanatory power of habits within the Theory of Planned Behavior (TPB), habits were pitted against competing variables emphasizing reflective thought processes and explained more variance in Internet usage than consciously processed outcome expectations or gratifications alone (see LaRose, 20IOa). Although most of these studies relied on correlational designs, some experimental work has offered evidence of a causal relationship between habits and tech usage (Tokunaga, 2013).

Along a similar timeline, addiction arose as a rival explanation for frequent use of online tech. However, many addiction studies sampled normal populations, leading to separate (but clearly overlapping) lines of inquiry on tech habits. In response, LaRose (2OIOa, 20Iob) proposed that so-called addictive uses among normal users were the result of deficient self-regulation. The deficient self-regulation model of media habits received support in a meta-analysis against a rival model of "problematic" Internet use (Tokunaga \& Rains, 20Io) and remains a viable explanation (Tokunaga, 2017). Despite the potential misnomer, tech addictions can also be interpreted through habitual neural mechanisms (Smith \& Graybiel, 20I6), and thereby aid in our understanding of (negative) habits. Consequently, this chapter reengages with the addiction perspective, but only as applied to normal populations (see also LaRose, 20Iob).

Parallel developments in the information systems literature, beginning with Limayem and Hirt (2003), found that habits were more powerful predictors of technology usage than reflective influences (e.g. derived from the Theory of Planned Behavior; TPB). Habits were later included in what is now a dominant theory in the field, the Unified Theory of Acceptance and Utilization of Technology (UTAUT2; Venkatesh, Thong, \& $\mathrm{Xu}, 2 \mathrm{I} 2)$. Similar to TPB, UTAUT2 focuses on a subset of beliefs that are theorized to determine the acceptance and utilization of consumer information systems (e.g. perform- ance, price value, and hedonic outcomes). Likewise, social norms are addressed through perceived social support for system use, and perceived behavioural control is accounted for through facilitating conditions and ease of use. Notably, habits are conceptualized on the same level as the TPBderived concepts, with past work demonstrating their capacity to explain both intentions and later information system use.

Together, the value of habit perspectives has been established in multiple areas of research on emergent technologies over the last two decades. Concurrent efforts have integrated habit research in communication with developments in social psychology, information systems, and neuroscience (LaRose, 20I0a, 20Iob, 2015). This synthesis included a variety of psychological studies that employed media habits as focal behaviours (e.g. Verplanken \& Orbell, 2003) and demonstrated the pervasiveness of media habits in daily life (e.g. Wood, Quinn, \& Kashy, 2002). Hence, from the telegraph to the television to the computer, technology habits have long operated as key heuristic cases for the study of habitual behaviour.

\section{Measurement Challenges}

As in other literatures, technology research rewards innovators of novel pursuits, even as publication delays and overlooked developments in allied areas lead to redundancy. This is especially so when researchers respond to the latest technological innovations and social trends. Accordingly, technology habit research was already well under way in both communication and information systems prior to the publication of the SelfReport Habit Index (SRHI; Verplanken \& Orbell, 2003). This led to differing, but intersecting, approaches to habit measurement that persist through today. Below, we document some of the pivotal issues that complicate tech habit operationalization before moving on to the implications for 
conceptualization.

Improvements upon Rubin's (1984) original habit question added statements that further conveyed the meaning of "habit" (e.g. "part of my routine") to produce reliable multiple-item scales. LaRose (2010a, 20IOb) proposed recognizing all dimensions of automatic behaviour (lack of awareness, attention, intention, and control). This led to a two dimensional solution termed deficient self-observation (connoting a lack of awareness, attention) and deficient self-reaction (intention, control) (LaRose, Kim, \& Peng, 20II; Tokunaga, 20I5). Deficient selfobservation parallels automaticity indicators in the SRHI, as became evident when SRHI items were integrated with the selfobservation measure (LaRose et al., 20II). However, the SRHI does not include selfreaction indicators (e.g. "I would find hard not to do", "That would require effort not to do it") in sufficient abundance to constitute a separate dimension.

Moreover, indicators of past behavioural frequency in the established SRHI are problematic for tech habit researchers who aim to predict usage and its consequences. This issue has led to frequency-independent measures derived from the SRHI (Bayer \& Campbell, 20I2; Bayer, Dal Cin, Campbell, \& Panek, 20I6; c.f., Gardner, Abraham, Lally, \& de Bruijn, 20I2). Such measures of tech habits reflect automaticity, but otherwise depart from the SRHI (see Chap. 3 in this volume, for a discussion of this issue).

Other tech habit measures emerged that placed greater emphasis on the lack of control and intention dimensions of automaticity. In particular, Limayem and Hirt (2003) produced a reliable multi-item measure for information systems researchers that contained statements that parallel some found in the SRHI. However, the measure also invoked the term "addiction" and so combines the two dimensions pro- posed by LaRose (20I0a, 20IOb), while once again blurring the distinction between normal tech habits and addictions. As noted above, current information systems research is informed by UTAUT2, which deploys a subset of items that emphasizes deficient self-reaction (vs. self-observation) in two of its three items.

An array of additional tech measures tap into habit dimensions indirectly. For instance, Facebook Intensity (Ellison, Steinfield, \& Lampe, 2007), which is defined as an intense relationship with Facebook, nonetheless contains some of the same basic dimensions as the SRHI. Specifically, the scale contains items relating to frequency of use and self-concept (e.g., "Facebook has become part of my daily routine"), paralleling the SRHI without using the habit label. Similar scales focusing on constructs such as "involvement" and "dependence" were developed for other online social behaviours that can appear obsessive (e.g. Walsh, White, \& Young, 20I0).

In addition, a plethora of technology addiction, problematic use, and compulsive use scales have been developed and adapted (see Tokunaga \& Rains, 20I6). As noted above, these scales are relevant since much of the extant research on problematic behaviour is focused on normal populations. Hence, such syndromes may be understood as habits that include deficient self-reaction items in their operational definitions (e.g. "try to cut down the amount of time you spend and fail?"; "stay online longer than intended?”) (LaRose, 20I0a; Tokunaga, 2015; Young, 1999), and so their scales encompass further examples of habit measures.

Most recently, researchers have adopted techniques outside of standard self- report (see also Habit Research in Action). The Response Frequency Measure of Media Habits (RFMMH; Naab \& Schnauber, 20I6) asks respondents which medium they would use to achieve certain goals (e.g. entertainment) under time pressure. Although moderately correlated with the SRHI, the relatively long (3-7 s) response intervals allow for thoughtful deliberation. In turn, the measure likely reflects goal-behaviour 


\section{HABIT RESEARCH IN ACTION Prospects for Tuning Down the Noise}

Given abundant overlap, empirical validation and integration among available measures is required, with special opportunities coming from less-obtrusive techniques. The RFMMH allows long reaction times that invite conscious reflection, and so methods that confine reactions to the millisecond range may be valuable in future work. Neuroscience studies sometimes employ reward devaluation to measure habit strength, an approach that could be applied to tech habits; for example, by removing the chroma cues or reducing the number of apps that are accessible from smartphones. Habit formation suppresses peripheral physiological responses and pupil dilation, which can be used to verify that users are responding to cues (Chen et al., 20I8). Researchers have drawn on functional Magnetic Resonance Imaging (fMRI) to examine attention habits in humans (Anderson, 20I6), as well as online media cognition (Meshi et al., 20I5), but this approach has yet to be extended to tech habits directly.

More generally, studies are needed that compare and contrast competing measurement approaches, along with their structures, head-to-head. The tech addiction literature has produced a multitude of instruments (e.g. over a dozen forms for measuring Internet addict-ion). In turn, addiction instruments have spawned offshoots covering specific devices, applications, and features within applications. In contrast to habit research, most of these instruments aspire to be diagnostic instruments. Because of this, addiction measures tend to include both the consequences of use (e.g. neglect of work, school, and family and social commitments) and the habitual processes that may produce those consequences, such as deficient self-observation and self-reaction. Separation of the two components (as in LaRose et al. 20II) might help to converge the two streams of research; for example, deficient self-reaction may be well correlated with addiction items that bespeak loss of self-control. Unobtrusive physiological, neurological, and reaction time measures requiring controlled lab conditions are advancing our knowledge of habits, but establishing their relationships (if any) to self-reported and digital measures is vital to understanding technology habits in real-world environments.

associations that are related to habit strength at moderate levels, but may be less valid than context-behaviour associations (Neal, Wood, Labrecque, \& Lally, 20I2). Separately, early research on news habits has found evidence of pupil dilation while individuals view habitually consulted sources (i.e. Facebook newsfeed), as compared to a control condition without cues (Chen, Tao, Liu, \& LaRose, 20I8).

\section{Conceptualization Challenges: Jingles, Jangles, Clatters, and Clamors}

Conflicting operational definitions emit conceptual noise. Tech habit research is thus subject to the jingle problem (Thorndike, 1904); that is, habit measures such as the SRHI and UTAUT2's habit scale share the same variable label, and even come from similar origins, yet their scales emphasize distinct dimensions of repetitive behaviour. By contrast, the SRHI and Facebook Intensity amount to a jangle problem (Kelley, 1927) with common measurement elements but different labels ("habits," "intensity"). To those well-known issues, we provisionally add two new terms to describe the conceptual noise in the field. Clatters are similar constructs that proceed from different, incompatible paradigms-but that aim to explain the same underlying phenomenon. For example, behavioural theories (e.g. UTAUT2, TPB) and disease models (e.g. 
addiction, compulsion) can be said to clatter with one another. Last, we might designate clamors: analogous concepts and scales developed in different fields of study-but take little notice of one another. For example, communication research can be said to clamor with information systems over competing models of tech habits. Despite the apparent cacophony, the jingles, jangles, clatters, and clamors nonetheless further our understanding of the mechanisms, antecedents, and consequences of tech habits.

\section{Causal Mechanisms of Overuse}

Rising above the noise, a fundamental question about the underlying mechanisms of tech behaviour remains actively debated. In particular, does highly repetitive technology use represent a pathology that originates with chronic dysphoria, personality traits, or neurological disorders, as "disease" models imply? Empirical research suggests that only a small population of clinically addicted Internet users exists (Alter, 20I7; Griffiths \& Kuss, 20I5; Tokunaga, 2017). Mental illness is generally marked by severe life consequences (e.g. losing friends or jobs), rather than "agree somewhat" with smartphone use complaints (KardefeltWinther et al., 2017; Van Deursen, Bolle, Hegner, \& Kommers, 20I5). Hence, the negative outcomes of technology addiction should only be correctable through professional therapeutic intervention. Yet, "addictive" use of new media is often resolved through spontaneous remission (LaRose, 20I5). Accordingly, among normal populations at least, the deficient self-regulation model presents a viable alter-native to the disease model (Tokunaga, 20I7).

A secondary question about causal ordering also helps to resolve the clamoring of behavioural and disease models. That is, do psychosocial problems such as depression and loneliness precede or follow the development of tech habits? Examining a body of research limited to correlational evidence, Tokunaga (20I7) concluded that either direction is possible for the causal arrow between problems and habits, with some evidence for cyclical patterns of causation. Hence, tech use that results in negative life consequences may originate in efforts to alleviate dysphoric states with rewarding tech behaviour (Kuss \& Billieux, 20I7). Unfortunately, certain users, these initial efforts may be hampered by deficient self-regulation and a spiral of mounting use (LaRose et al., 20II; van Rooij, Ferguson, van de Mheen, \& Schoenmakers, 20I7), especially when surrounded by encouraging others (Klimmt \& Brand, 20I7). Similarly, research suggests that deficient self-regulation can lead directly to negative consequences, as well as indirectly contribute through the frequency and duration of mobile use (Soror, Hammer, Steelman, Davis, \& Limayem, 20I5). To summarize, though tech behaviours rarely cross the threshold into problematic behaviour, habit is likely play a role in those cases.

Furthermore, more problematic tech behaviours might eventually be explained through fundamental habit mechanisms. Two distinct neural mechanisms (Smith \& Graybiel, 20I6), one involving ongoing interactions between automatic and deliberative processes (action-outcome habits), and another that acts independently of immediate reinforcement contingencies and defies self-control (stimulus-response habits), parallel the distinction between deficient selfobservation and deficient self- reaction sides of habit automaticity. Investigations that separate self-observation (awareness, attention) from self-reaction (intention, control) find that the two facets are related (LaRose et al., 20II; Tokunaga, 20I7; Van Deursen et al., 2015), although the directional arrows shift between studies and reciprocal causation remains a possibility. Therefore, future work is needed to examine whether normal and extreme users of technologies can be distinguished in terms of habitual cognition alone. 


\section{Antecedents and Consequences}

The conceptual noise above raises the question of whether some individuals are more susceptible to tech habits than others. A growing list of personality facets have received recent attention as antecedents of tech habits, including trait self-regulation, impulsiveness, and sensation seeking (Bayer, Dal Cin, et al., 20I6; Wilmer \& Chein, 2016). Demographic, motivational, and lifestyle variables add to the list of anteced- ents (Van Deursen et al., 2015). For instance, a seminal UTAUT2 study found a three-way interaction effect among age, gender, and prior experience on mobile Internet use, as well as correlations between habit strength and a range of situational factors (e.g. expected performance, social influence; Venkatesh et al., 20I2). In general, communication models have predicted habit strength from the expected outcomes of behaviour, selfefficacy, and depression, whereas information systems research has focused on user satisfaction and the various uses as further antecedents of tech habits (see LaRose, 2015, for a review).

Habit is also a powerful predictor of adoption and continuance for a long list of technologies, usually surpassing the strength of conscious intentions (LaRose, 2015). The sheer volume of use may partially account for both positive and negative effects, but there is reason to suspect that habit contributes beyond time commitment (Tokunaga, 20I6). Online safety habits contributed to the performance of protective behaviours (Tsai et al., 20I6), whereas texting habits predicted risky behaviour while driving and walking (Panek, Bayer, Dal Cin, \& Campbell, 2015) and responding to phishing emails (Vishwanath, Harrison, \& Ng, 20I6). Studies have also documented a variety of psychosocial problems that covary with tech habits, including depression, anxiety, loneliness, and neglect of important obligations (Tokunaga \& Rains, 20I6). Recent time series research points to habits (vs. time dis- placement) as the cause of functional difficulties involving social and professional life (Tokunaga, 20I6). Overall, research has introduced a wide range of antecedents and consequences of tech habits, though measurement limitations hamper the ability to disentangle key habitual mechanisms.

\section{What is Special about Tech Habits?}

Amid operational and conceptual diversity, extant research on tech habits has contributed to our understanding of habit acquisition and performance in daily life. Primarily, this body of work has focused on the role of habits-in competition with other individual factors-in predicting, explaining, and regulating user behaviour. More recent perspectives, however, question whether tech habits may change human cognition at a more basic level (Barr, Pennycook, Stolz, \& Fugelsang, 2015; Clayton, Leshner, \& Almond, 2015; LaRose, Lin, \& Eastin, 2003; Meshi, Tamir, \& Heekeren, 2015; Sparrow \& Chatman, 2013; Wilmer, Sherman, \& Chein, 20I7). National surveys (Anderson \& Perrin, 2017), daily diary (Wood et al., 2002), experience sampling (Hofmann, Vohs, \& Baumeister, 20I2), and digital tracking (Oulasvirta, Rattenbury, Ma, \& Raita, 20I2) studies all suggest that tech usage accounts for a substantial proportion of complex habits in daily life. But are these habits special, or do such societal and academic reactions to their presence reflect a default response to encountering the new?

Prior research on tech habits has neither fully articulated whether they are theoretically (in)distinguishable from other domains of habits nor related them to the broader literature on habits. The same neurocognitive mechanisms (e.g. Smith \& Graybiel, 20I6) presumably explain habitual Tinder swiping as well as they do Television clicking, tooth brushing, and wallet handling. Nonetheless, new-er tools might provide novel cues, contexts, and rewards to develop 
habits, and these factors may allow for habits to manifest in (seemingly) distinctive ways. From this vantage, the study of tech habits is the study of moderation effects on habitual processes; that is, how the cues, contexts, and outcome contingencies created by emergent technologies moderate habit formation, performance, and change.

Increasingly, technology research has questioned the common focus on particular technologies, rather than conceptualizing or manipulating their underlying attributes. In response, some researchers have called for a greater focus on "affordances" (Evans, Pearce, Vitak, \& Treem, 20I7; Fox \& McEwan, 20I7). At a basic level, affordances represent the "possibilities for action" separating a technology (or other objects) from a user (Evans et al., 20I7), typically oriented around the role of conscious or perceived functions. Nonetheless, many dimensions of technologies are "hidden" to the user (Gaver, I99I), and such dimensions may aid in the explication of tech habits. Rather than engendering a new form of cognition, tech habits may highlight how latent action possibilities influence habit mechanisms.

There are a variety of significant affordances (e.g. Fox \& McEwan, 20I7; Sundar, Jia, Waddell, \& Huang, 20I5) with the potential to influence habitual processes to some degree. On a related front, recent work has suggested that particular affordances may interact with online behaviours in the context of selfcontrol (Hofmann, Reinecke, \& Meier, 20I6). Hofmann et al. (20I6) highlighted four aspects that may contribute to the high level affective temptation seen in online media, including immediate gratifications, ubiquitous availability, attentional demands, and habitual usage itself. Separately, LaRose (2015) proposed a series of technological features that may influence habitual formation and change (e.g. anytime, anywhere, anonymity, anyhow). Ultimately, a parsimonious set of dimensions that will transcend specific technologies may be required to build an enduring framework- yet more groundwork is needed first.

Here, we take a sideward step by discussing how the components of a given behaviour may moderate habits via their fundamental elements: repetition, automaticity, and cueing in stable contexts (Orbell \& Verplanken, 20I5). The sections below explicate how the underlying components of a tech practices may influence habit action possibilities. In particular, we revisit cue and context properties of tech behaviours noted in past work, as well as outcome properties (Gardner, 2015), with the potential to moderate habit strength and performance. Certainly, the elements of repetition and automaticity are equally significant (and interwoven with the activation of contextual cues). However, we underline the latter elements due to the tendency of tech habits to challenge the meaning of "cued in stable contexts" (Orbell \& Verplanken, 20I5).

\section{Cue Properties}

Technologies that can be used more regularly than others inherently increase the opportunities for repeat behaviour, and thereby the likelihood and speed of habit formation. Therefore, portable technologies afford more opportunities (Schrock, 20I5) for a given cue to be acquired and activated due their continual presence. In addition to allowing for more cue exposure and rapid cue-behaviour associations, portable objects (e.g. phones, boom-boxes, newspapers) inhabit more environments and thus allow for a greater variety of spatial cues to become associated with a habit. Further, online capabilities substantially widen the range of behaviours that can be performed through a given tool. Paired together, portability and connectivity bring about new layers of potential cues (Wilmer \& Chein, 20I6). By providing an ever- present venue, an array of physical environments, and hyperlinks to bottomless information, emergent technologies open up extra opportunities for different cues to form in conjunction with 
said habit (Bayer, Campbell, \& Ling, 20I6).

Online technologies are not just ubiquitous; they also provide abundant action possibilities within and between devices, applications, and features. The same behavioural "chunks" (such as a smartphone "up swipe") may become associated with multiple responses and incorporated as the starting points in various behavioural scripts. Cues may be triggered internally or externally, including the "technical cues" that emanate from a technology itself (e.g. notifications, buzzes, sounds). These attentiondemanding triggers may provide for more salient cues than passive objects that lay in the background (Carden \& Wood, 20I8; Hofmann et al., 20I6). The rising influence of personalized algorithms, in particular, may hold important implications for cue learning in the not-too-distant future. Research has also turned attention inward to delineate the contribution of different sources of cues to aggregate tech habits (e.g. smartphone checking), such as the role of spatial, technical, and mental cues that compose the global "habit" (Bayer, Campbell, \& Ling, 20I6; Hall, 20I7). Following Neal et al. (20I2), future work is needed in the tech domain to empirically identify fundamental cue patterns across technologies and individuals. The de facto standardization of particular action sequences by popular technology interfaces points to the possibility of identifying a parsimonious set of cues underlying tech habits. In total, the same technology is likely to engender many different cues, and the same habit is likely to traverse many different technologies.

\section{Context Properties}

Habits are defined to occur in stable contexts, but what is a context? Within the habit literature, contexts are most commonly treated as particular locations, situational elements, and preceding actions (Wood, 20I7; Wood \& Neal, 2007). Tech habits, however, are noteworthy due to their "anytime, any- where" nature (LaRose, 20I5). Portability may produce a degree of what appears to be "context-independence" (Bayer \& Campbell, 2012). In many cases, it may be that the technology itself, or the embedded virtual environment, is the context. For example, the notification panel on a smartphone may operate as a context for interface habits. In other cases, it may be that the context is a mental state or frame of mind (in line with preceding action states), as opposed to a location or situation. For instance, the mental state of boredom may provide a context in which cues (e.g. loneliness) develop for checking the phone automatically. In this way, some tech habits are perhaps more similar to mental habits or attention habits than physical routines (Anderson, 20I6; Bayer, Campbell, \& Ling, 2016; Verplanken, Friborg, Wang, Trafimow, \& Woolf, 2007). Given the multidimensional nature of modern tech contexts, future research may require greater attention to context operationalization.

The wide spectrum of overlapping spatial, virtual, and mental contexts also create new opportunities for different habits to become interwoven with one another. Technologies that exhibit compatibility with other habits afford faster cue associations (cf., "innovation clusters", LaRose \& Hoag, I996). Individuals may "slip" back into old habits unless new habits are highly compatible with individual routines (Labrecque, Wood, Neal, \& Harrington, 20I7). Entry-level smartphone habits, such as placing and receiving voice calls, may become "gateways" (Oulasvirta et al., 20I2) to later habits such as texting and casual gaming. As a result, technologies that come with wide functionality, or comprehensiveness of use (Limayem, Hirt, \& Cheung, 2007), allow for discrete contexts (e.g. Gmail, Facebook, Snapchat) to appear in successive bursts or become embedded in scripts (Bayer, Campbell, \& Ling, 20I6). Continual access to related habits lend themselves to rapid "chunking", such as swiping and password entry during habit formation. Altogether, 
tech habits can satisfy a variety of needs concurrently (Naab \& Schnauber, 20I6; Sundar \& Limperos, 2013; Wang \& Tchernev, 20I2), and new habits are likely to develop faster, and remain stronger, as complements to old contexts.

\section{Outcome Properties}

Habit formation initially depends on the rate and size of the reward (Gardner, 2015; c.f., Wood, 20I7), whether the pellets dispensed by Skinner or tweets emitted by Twitter. Although online tech often provides immediate gratifications in ways similar to sweets (Hofmann et al., 20I6), such actions are not always rewarding. Rather, ever-present technologies offer instant outcomes (vs. rewards). Technologies that are characterized by certain reward schedules have the potential to facilitate stronger habitual conditioning. In particular, many technologies provide intermittent reward schedules, such as the act of checking a Twitter newsfeed that may have variable results (Vishwanath, 20I6) that can increase the pace of activation and ward against extinction (James \& Tunney, 20I7). The contemporary state of being permanently connected (Vorderer \& Kohring, 20I3) offers numerous sources of intermittent rewards at semi-random times, ranging from direct messages to news headlines (van Koningsbruggen, Hartmann, \& $\mathrm{Du}$, 20I7). Beyond primary reinforcement, versatile tools may produce secondary rewards (and punishment) associated with each catalytic cue. A cue (e.g. boredom) to check a smartwatch (e.g. Fitbit) may produce a reward by revealing the time, while also inducing secondary rewards and/or punishments (e.g. steps, badges) - all synchronously.

Emergent technologies thereby offer an amalgam of reward types, which can influence habitual processing in numerous ways. Since habit formation is especially sensitive to social rewards (Graybiel, 2008), technologies that provide social updates may allow for more powerful effects. Likewise, strict norms of social availability mean that individuals are expected to check for social updates - or face repercussions (Ling, 2012). Finally, technologies can modulate the level of delay in behavioural outcomes. Indeed, new media are defined by their interactivity (Sundar et al., 20I5), producing some combination of positive, neutral, and negative rewards with minimal delay in response to user feedback. By contrast, technologies that provide locks, passwords, and silencers act as reward buffers. Depending on the tool at hand and customized settings, technologies may tighten or loosen the cueoutcome loops that facilitate habit formation (LaRose, 20I5). The immediacy (e.g. clicks, beeps, bubbles, colors, numbers) of interactive habits may be established and extinguished more quickly than non-technical habits. However, once behaviours are codified as stimulus-response habits, they are relatively insensitive to negative outcomes (Smith \& Graybiel, 20I6; Wood, 20I7).

\section{From Problems to Prospects}

As demonstrated in the above sections, tech habit research is challenged by the inherently dynamic nature of technology itself, as well as what tech habits are perceived to be. Societal narratives defining new-er habits as technology habits correspond to the "technology-as-novelty" perspective (McOmber, 1999). Technology habits reformulate the ever-changing expectations, predispositions, and practices of a given society - in line with the sociological notion of habitus (Bourdieu, I977; Crossley, 2013; Papacharissi, Streeter, \& Gillespie, 2013). Once a tech habit becomes part of the takenfor-granted expectations, newer technologies inevitably supplant the old in society, creating a continuing stream of research within which theories of habits may be reexamined. In other words, the new habits of today become the built-in behaviours of tomorrow. The result is that "tech habits" end 
up with nebulous definitions, as indicated by the long list of keywords applied to contemporary technology behaviour.

The uncertain scope of tech habits is compounded by overlap with the addiction label, particularly given the widening purview of addictive behaviour (Alter, 20I7; Wiederhold, 20I8). Part of the problem is that the terms "habit" and "addiction" are often used loosely outside of their central literatures (and colloquially in broader society). Although we have focused on habits in this chapter, the addiction perspective continues to collide with tech habit research. In response to early disease model investigations of "excessive" usage (now considered average levels of use), there have been growing calls to reassess the assignment of the "addiction" label across disciplines (Billieux et al., 20I4; Griffiths \& Kuss, 2015; Tokunaga, 2015). Most recently, criticisms about technological and other controversial addictions were funneled into exclusion criterion to limit false positives (Kardefelt-Winther et al., 20I7).

Collectively, the ambiguity surrounding tech habits has implications for societies and researchers alike. Regardless of diagnostic rules, the substantial gap between the number of problem users and total users results in a conflicting narrative in society (Klimmt \& Brand, 20I7; Ryding \& Kaye, 20I7). Chun (2016) argues that, in the age of new media, habit has become even further pinned to the notion and lexicon of addiction in society. The expansive use of the addiction label may be viewed as part of the "habitus of the new" (Papacharissi et al., 2013), as a newly virtual society struggles with new conditions and potential threats. Tech habits underline the tendency of humans to fear change (sometimes reasonably; Alter, 20I7). That said, accounts of spontaneous remissions of seemingly destructive tech habits are often overlooked in favor of sensational stories, at least until those habits are taken-for-granted (Ling, 20I2). On the positive side, the uncertainty forces individuals and societies to reflect on the benefits and costs of tech habits (Lim, 20I3), including potential tech solutions to tech problems (Klimmt \& Brand, 2017). For example, recent updates include features that tweak the frequency or attractiveness of cues (e.g. greyscale interfaces, notification blockers), offering possibilities to enact habit change by changing the virtual environment (c.f., Carden \& Wood, 20I8).

Against this backdrop, it becomes clear that a more reflective and sustainable approach to researching tech habits is required. From a practical standpoint, different labels beget different literatures, splintering the progress being made and adding further uncertainty to the underlying mental processes. Here, we suggest the core question for tech habits is not whether basic mechanisms change as a function of newer tech (they presumably don't). Rather, the goal should be to explicate what components they employ that moderate the underlying elements of habit. None of the above components are unique to particular technologies - whether comic books or virtual reality-but they are often salient characteristics of those objects. In line with more conscious perceptions of technological affordances (Evans et al., 2017), the above components should be viewed along a spectrum. A smartphone is not the first technology tool to be portable-but it is more so than a laptop computer or a folding chair. Taking this perspective, "technology habits" represent a novel amalgam of behavioural components.

The question of how certain components affect habit mechanisms, and how various technologies align with those components, deserves empirical research. For instance, there is the potential to perform metaanalyses that reevaluate observed habit strength as a function of tech components. Going forward, a research agenda starts with research to further conceptualize and develop support for key components of tech habits, including how exactly they intersect with the basic elements of habit (Orbell \& Verplanken, 20I5). In line with other areas of tech research, studies seldom measure or 
manipulate technological attributes directly; conversely, the moderating components are typically limited to the discussion section. This may be partly due to the measurement challenges associated with extracting particular components, particularly while maintaining the real-world validity. By virtue of their complexity, however, tech habits reveal the built-in challenges involved in distinguishing standalone habits from more global sets of habits, chunks, and scripts. A century later, tech habits continue to echo Bryan and Harter's (I899) early study on the hierarchal nature of telegraph habits.

Tech habits thereby help to clarify the boundary conditions of habit mechanismsand offer innovative avenues for future research (Carden \& Wood, 20I8). Indeed, the prominence of tech habits during everyday life brings about abundant opportunities to study these components in naturalistic environments. Hence, emergent methods are slated to help habit researchers unpack some of the underlying elements and components discussed above. For instance, mobile and digital methodologies (Bayer, Ellison, Schoenebeck, Brady, \& Falk, 20I7; Harari et al., 20I6) are well-positioned to untangle the roles of spatial and virtual contexts in habit formation, while also allowing for testing hierarchal interactions of different habits (e.g. walking habits and swiping habits). Moreover, research on the moderating components of tech habits can assist in clarifying the lines between the normal habits and clinical problems. As a whole, tech habits remain well-positioned to explicate real-world habitual behaviour.

Future tech habit research should also move beyond predicting personal consequences associated with use to examine how habits contribute to broader societal concerns about technology. For example, recent research suggests that Facebook habit strength moderates the likelihood of individuals engaging in selective exposure to attitude consistent political content on the platform newsfeed (Chen et al., 2018). Among habitual users of the Facebook newsfeed, selective exposure was stronger when presented on a screen that contained familiar cues (e.g. standard logo, URL, color scheme, and layout) than comparable neutral cues. Since initial steps in a sequence of actions limit deliberations over later steps (Smith \& Graybiel, 20I6), this result might be explained as a weakening of critical reflect-ion on message content once an news script was cued. Restricted deliberation following the initiation of a context cue might also explain intense online experiences such as flow states (Tokunaga, 20I3) and immersive engagement (Kuru, Bayer, Pasek, \& Campbell, 20I7). When packaged into compact scripts, seemingly special habits paired with other unreflective forms of cognition may jointly contribute to the "addiction-like" aura of these habits (Bayer, Dal Cin, et al., 2016).

In sum, tech habits often seem "special", even when operating through the same basic elements of past telegraphic operators. For this reason, the deconstruction of habits into component parts may help to explain the societal skepticism, and potential pathologizing, of new habits. The realization that tech "addictions" are often just new-er habits that appear special is not new itself; back in the I970s, television was described as "the plug-in drug" (Winn, 1977). One does not need to be omniscient to presume that tech habits will continue to emerge that will pose theoretical and clinical obstacles to our future researchers and societies. Yet the way we approach this perpetual problem can change.

\section{Conclusion}

This chapter mapped the trajectory of contemporary tech habits, an umbrella term encompassing a growing array of new media behaviours. Due to their ubiquitous role in everyday life, tech behaviours contribute to our understanding of dynamic habits by challenging the preconceptions of standard habitual action-at least at first. Each new 
layer of innovation reinvigorates old concerns and promises related to the impacts of emergent technology on individual and societal well-being (Carbonell \& Panova, 20I7; Ryding \& Kaye, 20I7; Wilmer et al., 20I7). To be sure, there are other innovations that are also deserving to represent the "tech habits" mantle from a mechanical standpoint (e.g. medical or transportation inventions). Those pertaining to daily information, communication, and leisure activities, however, often receive an outsized share of concerns compared to their tech brethren.

As a consequence, tech habits offer a valuable case for considering the positive and negative outcomes that result from a perennial research focus on new-er habits. On the positive side, research has demonstrated the immense role of habit in tech adoption and usage, as well as key antecedents and consequences-all while encountering successive waves of transformative inventions. Simultaneously, their behavioural complexity and real-world relevance makes them revealing as heuristic cases, affirming the adaptive power of habits in societal progress (or lack thereof; James, I890). In the process, we suggest that research on tech habits helps to illuminate the hidden mechanisms and moderators supporting habitual behaviour at large.

Looking forward, this chapter suggests that researchers place greater emphasis on the underlying components of habitual behaviour, rather than the fleeting features of the present. Why does deconstructing the gears of tech habits matter? We propose that examining how newer technologies rely on certain components that exaggerate habitual cognition may help to explain, and to some extent justify, the uncertainty surrounding them in both societal and academic dis-course. Novel combinations of cues, contexts, and outcomes can make a technology habit look powerfully, and perhaps deceivingly, special. With this in mind, future research should examine newer habits through more generalizable paradigms, not limited to particular devices or applications, and avoid spinning the same flywheels over and over again. 


\section{References}

Alter, A. (2017). Irresistible: The rise of addictive technology and the business of keeping us hooked. New York: Penguin Press.

Anderson, B. A. (2016). The attention habit: How reward learning shapes attentional selection. Annals of the New York Academy of Sciences, I369(I), 24-39. https://doi.org/IO.IIII/ nyas.I2957

Anderson, M., \& Perrin, A. (2017). Tech adoption climbs among older adults. Pew Research Center, (May), I-22.

Barr, N., Pennycook, G., Stolz, J. A., \& Fugelsang, J. A. (2015). The brain in your pocket: Evidence that smartphones are used to supplant thinking. Computers in Human Behavior, 48, 473-48o. https://doi.org/IO.IOI6/j.chb.2015.02.029

Bayer, J. B., \& Campbell, S. W. (2012). Texting while driving on automatic: Considering the frequency-independent side of habit. Computers in Human Behavior, 28(6), 2083-2090. https://doi. org/IO.IOI6/j.chb.2012.06.0I2

Bayer, J. B., Campbell, S. W., \& Ling, R. (2016). Connection cues: Activating the norms and habits of social connectedness. Communication Theory, 26, I28-I49. https://doi.org/IO.IIII/ comt.I2090

Bayer, J. B., Dal Cin, S., Campbell, S. W., \& Panek, E. (2016). Consciousness and self-regulation in mobile communication. Human Communication Research, 42, 71-97.

https://doi.org/IO.IIII/ hcre.I2067

Bayer, J. B., Ellison, N., Schoenebeck, S., Brady, E., \& Falk, E. B. (20I7). Facebook in context(s): Measuring emotional responses across time and space. New Media \& Society, 20, I047-I627. https:// doi.org/IO.II77/I46I4448I668I522

Billieux, J., Philippot, P., Schmid, C., Maurage, P., De Mol, J., \& Van der Linden, M. (2O14). Is dysfunctional use of the mobile phone a behavioural addiction? Confronting symptombased versus process-based approaches. Clinical Psychology \& Psychotherapy, 22, 460.

Bourdieu, P. (1977). Outline of a theory of practice. Cambridge: Cambridge University Press. Bryan, W., \& Harter, N. (I899). Studies on the telegraphic language: The acquisition of a hierarchy of habits. Psychological Review, 6(4), 345-375. https://doi.org/IO.IO37/hoo73II7

Carbonell, X., \& Panova, T. (2017). A critical consideration of social networking sites' addiction potential. Addiction Research and Theory, 25(I), 48-57. https://doi.org/IO.IO80/16066359.2016.II97915

Carden, L., \& Wood, W. (2018). Habit formation and change. Current Opinion in Behavioral Sciences, 20, II7-I22. https://doi.org/Io.IoI6/j.cobeha.2017.I2.009

Chen, C. C., Tao, C. C., Liu, M., \& LaRose, R. (2018). Automatic processes in selective news expo- sure among habitual Facebook users in Taiwan. Prague, CZ: International Communication Association.

Chun, W. H. K. (2016). Updating to remain the same: Habitual new media. Cambridge, MA: MIT Press.

Clayton, R. B., Leshner, G., \& Almond, A. (2015). The extended iSelf: The impact of iPhone separation on cognition, emotion, and physiology. Journal of Computer-Mediated Communication, 2O(2), II9-I35. https://doi.org/IO.IIII/jcc4.I2IO9

Clements, J. A., \& Boyle, R. (2018). Compulsive technology use: Compulsive use of mobile applications. Computers in Human Behavior, Forthcoming(May), 34-48. https://doi.org/IO.IOI6/j. chb.20I8.05.018 
Crossley, N. (20I3). Habit and habitus. Body E Society, I9(2-3), I36-I6I. https://doi.org/IO.II7 7/1357034XI2472543

DeLuca, R. (20II). Post roads E iron horses: Transportation in Connecticut from colonial times to the age of steam. Middletown, CT: Wesleyan University Press.

Ellison, N. B., Steinfield, C., \& Lampe, C. (2007). The benefits of Facebook "friends:" social capital and college students' use of online social network sites. Journal of ComputerMediated Communication, I2, II43-II68.

Evans, S. K., Pearce, K. E., Vitak, J., \& Treem, J. W. (20I7). Explicating affordances: A conceptual framework for understanding affordances in communication research. Journal of Computer-Mediated Communication, 22(I), 35-52. https://doi.org/IO.IIII/jcc4.I2I8o

Fox, J., \& McEwan, B. (20I7). Distinguishing technologies for social interaction: The perceived social affordances of communication channels scale. Communication Monographs, 84(3), 298-3I8. https://doi.org/I0.I080/0363775I.20I7.I3324I8

Gardner, B. (20I5). A review and analysis of the use of "habit" in understanding, predicting and influencing health-related behaviour. Health Psychology Review, 9, 277-295.

Gardner, B., Abraham, C., Lally, P., \& de Bruijn, G.-J. (20I2). Towards parsimony in habit measurement: Testing the convergent and predictive validity of an automaticity subscale of the self-report habit index. International Journal of Behavioral Nutrition and Physical Activity, 9(I), IO2. https://doi.org/IO.II86/I479-5868-9-IO2

Gaver, W. W. (199I). Technology affordances. Proceedings of the SIGCHI Conference on Human Factors in Computing Systems Reaching through Technology-CHI '9I (pp. 79-84). https:// doi.org/IO.II45/I08844.IO8856

Graybiel, A. M. (2008). Habits, rituals, and the evaluative brain. Annual Review of Neuroscience, 3I(I), 359-387. https://doi.org/IO.II46/annurev.neuro.29.05I605.II285I

Griffiths, M. D., \& Kuss, D. J. (2015). Online addictions: Gambling, video gaming, and social networking. In S. Sundar (Ed.), The handbook of the psychology of communication technology (pp. 384-403). New York: Wiley. https://doi.org/IO.IO02/978III8426456.chI7

Hall, J. (2017). The experience of mobile entrapment in daily life. Journal of Media Psychology, 29(3), I48-I58. https://doi.org/IO.IO27/I864-IIO5/aooo228

Harari, G. M., Lane, N. D., Wang, R., Crosier, B. S., Campbell, A. T., \& Gosling, S. D. (2016). Using smartphones to collect behavioral data in psychological science: Opportunities, practical considerations, and challenges. Perspectives on Psychological Science, II(6), 838854. https:// doi.org/IO.II77/I74569I6I6650285

Hofmann, W., Reinecke, L., \& Meier, A. (20I6). Of sweet temptations and bitter aftertaste: Selfcontrol as a moderator of the effects of media use on well-being. In L. Reinecke \& M. B. Oliver (Eds.), The Routledge handbook of media use and well-being (pp. 2II-222). New York: Routledge.

Hofmann, W., Vohs, K. D., \& Baumeister, R. F. (20I2). What people desire, feel conflicted about, and try to resist in everyday life. Psychological Science, 23(6), 582-588. https://doi. org/IO.II77/09567976I2437426

James, W. (I890). The principles of psychology, Vol. 2. NY, US: Henry Holt and Company. James, R. J. E., \& Tunney, R. J. (20I7). The need for a behavioural analysis of behavioural addictions. Clinical Psychology Review, 52, 69-76. https://doi.org/Io.IoI6/j.cpr.20I6.II.oIo 
Kardefelt-Winther, D., Heeren, A., Schimmenti, A., van Rooij, A., Maurage, P., Carras, M., et al. (20I7). How can we conceptualize behavioural addiction without pathologizing common behaviours? Addiction, II2(IO), I709-I715. https://doi.org/IO.IIII/add.I3763

Kelley, T. L. (1927). Interpretation of educational measurements. Journal of Applied Psychology, I2, I6o. https://doi.org/IO.IO37/hoo68663

Klimmt, C., \& Brand, M. (20I7). Permanence of online access and internet addiction. In P. Vorderer, D. Hefner, L. Reinecke, \& C. Klimmt (Eds.), Permanently online, permanently connected: Living and communicating in a POPC World (pp. 6I-7I). New York: Taylor \& Francis.

Kuru, O., Bayer, J. B., Pasek, J., \& Campbell, S. W. (20I7). Understanding and measuring mobile Facebook use: Who, why, and how? Mobile Media and Communication, 5(I), IO2. https://doi.org/IO.II77/2050157916678269

Kuss, D. J., \& Billieux, J. (20I7). Technological addictions: Conceptualization, measurement, etiology and treatment. Addictive Behaviors, 64, 23I-233. https://doi.org/IO.IOI6/j.addbeh.20I6.04.005

Labrecque, J. S., Wood, W., Neal, D. T., \& Harrington, N. (20I7). Habit slips: When consumers unintentionally resist new products. Journal of the Academy of Marketing Science, 45(I), II9I33. https://doi.org/IO.IOO7/sII747-0I6-0482-9

LaRose, R. (2010a). The problem of media habits. Communication Theory, 20, 194-222.

LaRose, R. (20IOb). The uses and gratifications of internet addiction. In K. Young \& C. N. de Abreu (Eds.), Internet addiction handbook (pp. 55-72). New York: Wiley.

LaRose, R. (20I5). The psychology of interactive media habits. In S. Sundar (Ed.), The handbook of the psychology of communication technology (pp. 365-383). New York: Wiley.

LaRose, R., \& Hoag, A. (1996). Organizational adoptions of the Internet and the clustering of innovations. Telematics and Informatics, I3(I), 49-6I.

LaRose, R., Kim, J., \& Peng, W. (20II). Social networking: Addictive, compulsive, problematic, or just another media habit? In Z. Papacharissi (Ed.), A networked self (pp. 59-8I). New York: Routledge.

LaRose, R., Lin, C. A., \& Eastin, M. S. (2003). Unregulated internet usage: Addiction, habit, or deficient self-regulation? Media Psychology, 5(3), 225-253.

Lim, S. S. (2013). On mobile communication and youth "deviance": Beyond moral, media and mobile panics. Mobile Media and Communication, I(I), 96-IOI. https://doi. org/IO.II77/2050I579I2459503

Limayem, M., \& Hirt, S. G. (2003). Force of habit and information systems usage: Theory and initial validation. Journal of the Association for Information Systems, 4(4), 65-97. https://doi. org/IO.IOI6/j.actbio.2005.04.004

Limayem, M., Hirt, S. G., \& Cheung, C. M. K. (2007). How habit limits the predictive power of intention: The case of information systems continuance. MIS Quarterly, 3I(4), 705-737.

Ling, R. (2012). Taken for Grantedness: The embedding of mobile communication into society. Cambridge, MA: MIT Press.

McOmber, J. B. (1999). Technological autonomy and three definitions of technology. Journal of Communication, 49(3), I37-I53. https://doi.org/IO.IIII/j.I460-2466.I999.tbo2809.x

Meshi, D., Tamir, D. I., \& Heekeren, H. R. (2015). The emerging neuroscience of social media. Trends in Cognitive Sciences, I9(I2), 77I-782. https://doi.org/IO.IOI6/j.tics.20I5.09.004

Naab, T. K., \& Schnauber, A. (20I6). Habitual initiation of media use and a response-frequency 
measure for its examination. Media Psychology, I9(I), I26-I55. https://doi.org/IO.IO80/I52 I3269.20I4.95IO55

Neal, D. T., Wood, W., Labrecque, J. S., \& Lally, P. (2012). How do habits guide behavior?

Perceived and actual triggers of habits in daily life. Journal of Experimental Social

Psychology, 48, 492-498.

Orbell, S., \& Verplanken, B. (20I5). The strength of habit. Health Psychology Review, 9, 3II-3I7. https://doi.org/I0.IO80/I7437199.20I4.99203I

Oulasvirta, A., Rattenbury, T., Ma, L., \& Raita, E. (2012). Habits make smartphone use more pervasive. Personal and Ubiquitous Computing, I6(I), IO5-II4. https://doi.org/IO.IO07/ soo779OII-O4I2-2

Panek, E. T., Bayer, J. B., Dal Cin, S., \& Campbell, S. W. (2015). Automaticity, mindfulness, and self-control as predictors of dangerous texting behavior. Mobile Media and Communication, 3(3), 383. https://doi.org/I0.II77/2050I57915576046

Papacharissi, Z., Streeter, T., \& Gillespie, T. (2013). Culture digitally: Habitus of the new. Journal of Broadcasting and Electronic Media, 57(4), 596-607. https://doi.org/I0.IO80/o8838I5I.20 I3.846344

Rubin, A. M. (1984). Ritualized and instrumental television viewing. Journal of Communication, 34(3), 67-77. https://doi.org/IO.IIII/j.I460-2466.I984.tbo2I74.x

Ryding, F. C., \& Kaye, L. K. (20I7). "Internet addiction": A conceptual minefield. International Journal of Mental Health and Addiction, I6, 225-232. https://doi.org/I0.I007/ sII469-0I7-98II-6

Schrock, A. R. (2015). Communicative affordances of mobile media: Portability, availability, locatability, and multimediality. International Journal of Communication, 9, I229-I246.

Smith, K. S., \& Graybiel, A. M. (2016). Habit formation. Dialogues in Clinical Neuroscience, I8(I), 33-43. https://doi.org/IO.IIII/clr.I2458_III

Soror, A. A., Hammer, B. I., Steelman, Z. R., Davis, F. D., \& Limayem, M. M. (20I5). Good habits gone bad: Explaining negative consequences associated with the use of mobile phones from a dual-systems perspective. Information Systems Journal, 25(4), 403-427. https://doi. org/IO.IIII/isj.I2065

Sparrow, B., \& Chatman, L. (2013). Social cognition in the internet age: Same as it ever was? Psychological Inquiry, 24(4), 273-292. https://doi.org/I0.I080/I047840X.2013.827079

Sundar, S., Jia, H., Waddell, T. F., \& Huang, Y. (2015). Toward a theory of interactive media effects (TIME): Four models for explaining how Interface features affect user psychology. In The handbook of the psychology of communication technology (pp. 47-86). https://doi.org/IO.IOO2/978III8426456

Sundar, S., \& Limperos, A. M. (2013). Uses and Grats 2.0: New gratifications for new media. Journal of Broadcasting E Electronic Media, 57, 504-525. https://doi.org/I0.I080/08838I5 I.20I3.845827

Thorndike, E. L. (1904). The newest psychology. Educational Review, 28, 217-227.

Tokunaga, R. S. (2013). Engagement with novel virtual environments: The role of perceived novelty and flow in the development of the deficient self-regulation of internet use and media habits. Human Communication Research, 39(3), 365-393. https://doi.org/IO.IIII/hcre.I2008

Tokunaga, R. S. (20I5). Perspectives on internet addiction, problematic internet use, and deficient self-regulations. Communication Yearbook, 39, I3I-I6I. 
Tokunaga, R. S. (2016). An examination of functional difficulties from internet use: Media habit and displacement theory explanations. Human Communication Research, 42(3), 339370. https://doi.org/IO.IIII/hcre.I208I

Tokunaga, R. S. (2017). A meta-analysis of the relationships between psychosocial problems and internet habits: Synthesizing internet addiction, problematic internet use, and deficient self- regulation research. Communication Monographs, 84(4), 423-446. https://doi.org/IO.IO80/o 363775I.2017.1332419

Tokunaga, R. S., \& Rains, S. (20I0). An evaluation of two characterizations of the relationships between problematic internet use, time spent using the internet, and psychosocial problems. Human Communication Research, 36(4), 5I2-545. https://doi. org/IO.IIII/j.I4682958.20I0.0I386.x

Tokunaga, R. S., \& Rains, S. A. (2016). A review and meta-analysis examining conceptual and operational definitions of problematic internet use. Human Communication Research, 42(2), I65-I99. https://doi.org/IO.IIII/hcre.I2075

Tsai, H. S., Jiang, M., Alhabash, S., LaRose, R., Rifon, N. J., \& Cotten, S. R. (2016). Understanding online safety behaviors: A protection motivation theory perspective. Computers \& Security, 59, I38-I50. https://doi.org/IO.IOI6/j.cose.2016.02.009

Van Deursen, A. J. A. M., Bolle, C. L., Hegner, S. M., \& Kommers, P. A. M. (2015). Modeling habitual and addictive smartphone behavior: The role of smartphone usage types, emotional intelligence, social stress, self-regulation, age, and gender. Computers in Human Behavior, 45, 4II-420. https://doi.org/IO.IOI6/j.chb.20I4.I2.039

van Koningsbruggen, G. M., Hartmann, T., \& Du, J. (2017). Always on? Explicating impulsive influences on media use. In P. Vorderer, D. Hefner, L. Reinecke, \& C. Klimmt (Eds.), Permanently online, permanently connected: Living and communicating in a POPC world (pp. 5I-60). New York: Taylor \& Francis.

van Rooij, A. J., Ferguson, C. J., van de Mheen, D., \& Schoenmakers, T. M. (20I7). Time to abandon internet addiction? Predicting problematic internet, game, and social media use from psychosocial Well-being and application use. Clinical Neuropsychiatry, I4(I), II3-I2I.

Venkatesh, V., Thong, J., \& Xu, X. (20I2). Consumer acceptance and user of information technology: Extending the unified theory of acceptance and use of technology. MIS Quarterly, 36(I), I57-I78. https://doi.org/I0.IIII/j.I365-2729.2006.00I63.X

Verplanken, B., Friborg, O., Wang, C. E., Trafimow, D., \& Woolf, K. (2007). Mental hab- its: Metacognitive reflection on negative self-thinking. Journal of Personality and Social Psychology, 92(3), 526-54I. https://doi.org/IO.I037/0022-35I4.92.3.526

Verplanken, B., \& Orbell, S. (2003). Reflections of past behavior: A self-report index of habit strength. Journal of Applied Social Psychology, 33(6), I313-1330.

Vishwanath, A. (20I6). Mobile device affordance: Explicating how smartphones influence the outcome of phishing attacks. Computers in Human Behavior, 63, 198-207. https://doi. org/I0.IOI6/j.chb.20I6.05.035

Vishwanath, A., Harrison, B., \& Ng, Y. J. (2016). Suspicion, cognition, and automaticity model of phishing susceptibility. Communication Research. https://doi.org/IO.II77/00936502I5627483

Vorderer, P., \& Kohring, M. (2013). Permanently online: A challenge for media and communication research. International Journal of Communication, 7(I), I88-I96. 
Walsh, S., White, K. M., \& Young, R. M. (20I0). Needing to connect: The effect of self and others on young people's involvement with their mobile phones. Australian Journal of Psychology, 62(4), 194-203.

Walther, J. B., \& Valkenburg, P. M. (20I7). Merging mass and interpersonal communication via interactive communication technology: A symposium. Human Communication Research, 43(4), 4I5-423. https://doi.org/IO.IIII/hcre.I2I2O

Wang, Z., \& Tchernev, J. M. (2012). The 'myth' of media multitasking: Reciprocal dynamics of media multitasking, personal needs, and gratifications. Journal of Communication, 2004, 493-5I3. https://doi.org/IO.IIII/j.I460-2466.20I2.0I64I.X

Wiederhold, B. K. (20I8). Stop scrolling, start living: The growing reality of internet addiction disorder. Cyberpsychology, Behavior and Social Networking, 2I(5), 279-28o. https://doi. org/I0.I089/cyber.20I8.29III.bkw

Wilmer, H. H., \& Chein, J. M. (2016). Mobile technology habits: A patterns of association among device usage, intertemporal preference, impulse control, and reward sensitivity. Psychonomic Bulletin and Review, 23(5), I607-I6I4. https://doi.org/I0.3758/sI3423-0I6-IOII-Z

Wilmer, H. H., Sherman, L. E., \& Chein, J. M. (2017). Smartphones and cognition: A review of research exploring the links between mobile technology habits and cognitive functioning. Frontiers in Psychology, 8, I-I6. https://doi.org/I0.3389/fpsyg.2017.00605

Winn, M. (1977). The plug-in drug: Television, children, \& the family. New York: Penguin.

Wood, W. (2017). Habit in personality and social psychology. Personality and Social Psychology Review, 2I(4), 389-403. https://doi.org/IO.II77/I0888683I7720362

Wood, W., \& Neal, D. T. (2007). A new look at habits and the habit-goal Interface. Psychological Review, II4(4), 843-863. https://doi.org/I0.I037/o033-295X.II4.4.843

Wood, W., Quinn, J. M., \& Kashy, D. A. (2002). Habits in everyday life: Thought, emotion, and action. Journal of Personality and Social Psychology, 83(6), I28I-I297.

Young, K. S. (1999). Evaluation and treatment of internet addiction. In Innovations in clinical practice: A source book (Vol. I7, pp. I9-3I). 